\title{
Wind Turbines Based on Doubly Fed Induction Generator in Coordinate Operation with a STATCOM
}

\author{
A. F. Carneiro, M. D. Lucas and F. K. A. Lima \\ Power Electronics Applications \& Energy Systems Integration Laboratory (LAPIS) \\ Federal University of Ceara (UFC) \\ Campus of Pici - Fortaleza, 60455-760 Ceará (Brazil) \\ Phone/Fax number0055 85 3366-9580 / +0055 85 3366-9574, e-mail: alexandrecarneiro@edu.unifor.br, \\ marlosdll@gmail.com, klima@dee.ufc.br
}

\begin{abstract}
This paper approach the study of Doubly-Fed Induction Generators (DFIG) next to the device FACTS (STATCOM), connected directly on the bus CA transmission line. The DFIG, in your structure, is composed for two converters of the type back-to-back, these responsible by control the voltage at the DC link and the power flows in the network. Through a STATCOM and the use technical control based on pq Theory, there are at system the bracket voltage control on the bus CA on which the DFIG is connected. This work will address the voltage regulation at PCC (common connection point) in case of disturbances on system. Simulation Results, utilizing the computational tool PSCAD/EMTCD, are submitted to prove effectiveness the use of STATCOM at the proposed system.
\end{abstract}

\section{Key words}

Doubly-Fed Induction Generator, STATCOM, Vector control, Power grid, Power quality

\section{Introduction}

The wind power comes gaining growing more prominence in the scenario Brazilian and global as a source of alternative energy. In Brazil, this is due to larger investments and incentives from the Brazilian government made in last years, providing the development of several studies on the technologies of wind turbines. The incomparable quality of the effect of strong winds, especially on the coast of Northeast Brazil, makes this country is a strategic point to entry of new technologies Latin America. In this paper, we will use the Doubly-Fed Induction Generator (DFIG). Among the machines also used in Wind generation, for example, the Permanent Magnet Synchronous Generator, Wound Rotor Synchronous Generator etc., the DFIG is the generator who is comes gaining space on the world stage [1].

According to recent data (2013) published by ANNEL, the installed capacity in Brazil from a little over $29 \mathrm{MW}$ in 2005, to 2,109.36 MW in September 2013. For next years is anticipated an increase around $7.6 \mathrm{GW}$ the Brazilian energy matrix, from wind farms still dead. Currently, the operating enterprises realize representing 97 wind farms that represent $1.59 \%$ of the total energy matrix in Brazil. It is important to remember that currently the Brazilian demand is approximately $133 \mathrm{GW}$, where $8.1 \mathrm{GW}$ of which are imported from countries such as: Paraguay, Argentina, Venezuela and Uruguay [2].

Looking at Fig. 1 it can be seen the characteristic curve of the evolution of installed capacity from wind sources in Brazil [2]. The years 2005 to 2013 using actual data, while subsequent years are based on statistical forecasting growth depending on contracts performed in auctions and in the free energy market.

With the increased penetration of wind sources in the Brazilian energy matrix, new challenges make it necessary, for example, the quality assurance of energy coming from these sources.

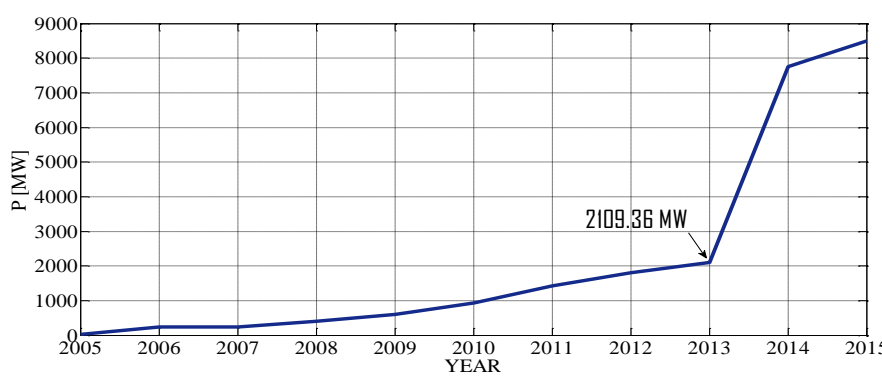

Fig. 1. Evolution of installed capacity in Brazil

This article aims to investigate the dynamics of power oscillations in the system resulting from the use of DFIG based wind turbines, as well as to verify the influence of the device STATCOM for damping these oscillations. A model was developed using software PSCAD / EMTDC to prove the theory presented. 


\section{Doubly Fed Induction Generator}

The basic structure of a wind turbine equipped with DFIG is shown in Fig. 2. The stator of the machine is connected directly to the grid while the rotor is connected to the network via two converters based on power electronics: the converter side of the machine (RSC) and the grid side converter (GSC).

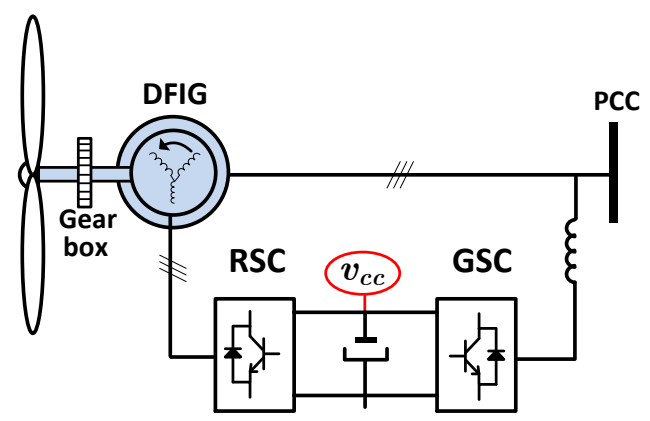

Fig. 2. Turbine equipped with DFIG.

These are connected topology in back-to-back through a DC link. The RSC is responsible for the control of active and reactive power of the stator of the machine, while the GSC is responsible for controlling the DC link voltage, beyond reactive power in this branch [3].

One of the advantages of using technology DFIG is directly related to the converters because they allow bidirectional flow of power and are designed only for a portion of the rated power of the generator. Once the DFIG connected directly to the grid through the stator, most of the machine's power will flow through there. The other part of the energy will flow through the converters RSC and GSC. These converters must be specified for a power of between $25 \%$ and $30 \%$ of the nominal power of the machine [1].

A widely used technique to control the RSC DFIG is the vector control driven by the field. Through this control it is possible to control the active and reactive power independently of the stator, this means that there is no coupling between the controls.

This technique is as follows: once considered the alignment between the stator magnetic flux vector and the direct axis, as shown in Fig. 3, the control variables is converted into DC signals, thus making it possible to control from PI controllers.

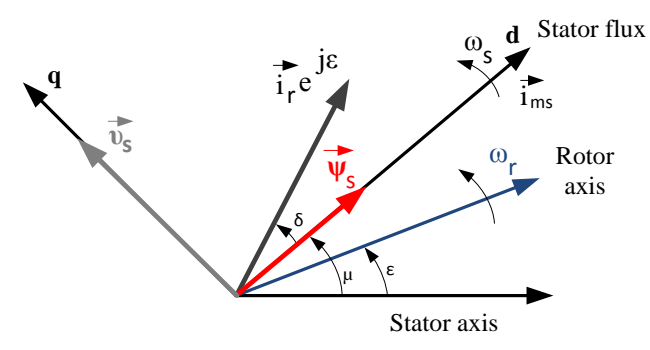

Fig. 3. Phasor Diagram in dq reference.
Whereas the stator resistance in DFIG can be neglected for the purposes of this analysis, the stator voltage vector $\vec{v}_{s}$ can be considered by $90^{\circ}$ in advance of the vector magnetic flux of the stator, as shown in Fig. 3. The rotor current vector $\overrightarrow{\mathrm{l}}_{\mathrm{r}} \mathrm{e}^{\mathrm{j} \varepsilon}$ is referenced to the coordinates $\mathrm{dq}$ stator current vector and the vector magnetization of the machine is represented by $\overrightarrow{1}_{\mathrm{ms}}$.

Equation (1) represents the electromagnetic torque of the machine.

$$
T_{e}=\frac{3}{2} p\left(\psi_{s q} i_{s d}-\psi_{s d} i_{s q}\right)
$$

Since the quadrature component of the stator magnetic flux vector is zero $\left(\psi_{s q}=0\right)$, expression (1) can be rewritten as:

$$
T_{e}=-\frac{3}{2} p \psi_{s d} i_{s q} .
$$

Furthermore, if $\boldsymbol{\psi}_{\boldsymbol{s q}}=\mathbf{0}$, is possible to write:

$$
i_{s q}=\frac{L_{m}}{L_{s}} i_{r q}
$$

Thus, the combination of (2) and (3) results in:

$$
T_{e}=\frac{3}{2} p \frac{L_{m}}{L_{s}} \psi_{s d} i_{r q}
$$

From (4) it can be concluded that by controlling the quadrature component of the rotor current, directly controls the torque of the electric machine.

Combining equations of voltages and magnetic flux in the stator of DFIG, written in dq synchronous reference, and yet, considering the vector control technique shown in Fig. 3 it is possible to write a model for steady state, as shown in the following expressions [3]:

$$
\begin{gathered}
i_{s d}(s)=\frac{1}{L_{s} \omega_{s}} v_{s q}-\frac{L_{m}}{L_{s}} i_{r d} \\
i_{s q}(s)=-\frac{L_{m}}{L_{s}} i_{r q}
\end{gathered}
$$

In equations (5) and (6) it is possible to observe the dependence between the currents of the rotor and axes stator direct and quadrature respectively. This model suggests that, in steady state, the DFIG can be considered as a current source controlled by current.

The machine side converter is responsible for the control of active and reactive power of the stator. Since the stator active power can be written as:

$$
p_{s}=v_{s d} i_{s d}+v_{s q} i_{s q}
$$

Being $v_{s d}=0$, according to Fig. 3, is obtained:

$$
p_{s}=v_{s q} i_{s q}
$$

Combining (6) and (8) can be written $p_{s}$ in function of $i_{r q}$.

$$
p_{s}=-\frac{L_{m}}{L_{s}} v_{s q} i_{r q}
$$

From (4) and (9) it can be seen that by controlling the quadrature component of the rotor current, one can control the electromagnetic torque as the active power in the stator. 
The same can be done for the reactive power of the stator, obtaining (10):

$$
q_{s}=-\frac{L_{m}}{L_{s}} v_{s q}\left(\frac{v_{s q}}{\omega_{s} L_{m}}-i_{r d}\right)
$$

From equation (10) it is possible to verify the control of reactive power $\mathrm{q}_{\mathrm{s}}$ by controlling the direct component of the rotor current, once admitted to the stator voltage with amplitude and constant frequency. The first part into parêntese (10) is, for definition, magnetization current on the machine who, in steady state, is constant.

Fig. 4 shows the block diagram for the control of the RSC may be obtained through the modeling described in [3].

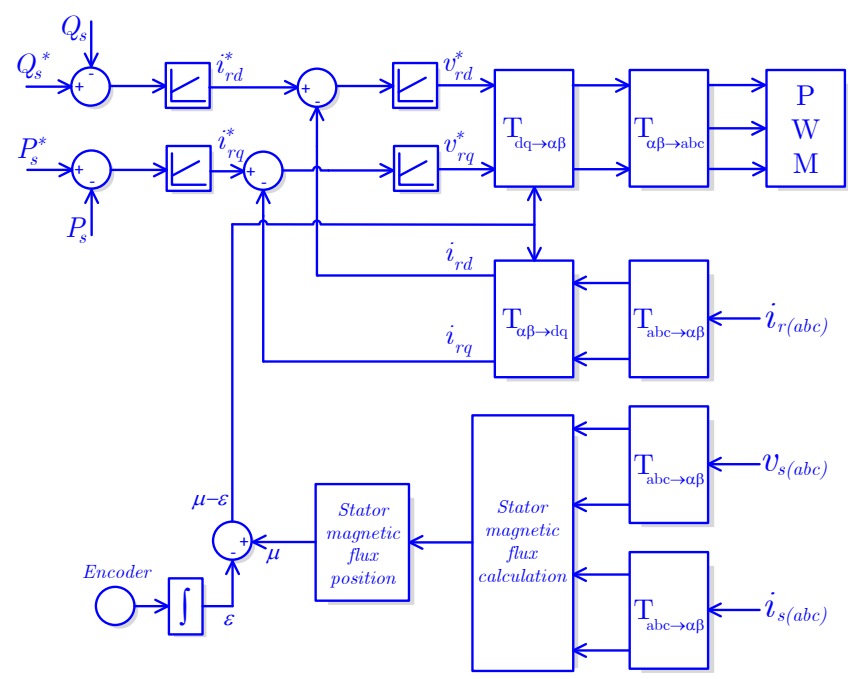

Fig. 4. RSC control [2].

Already block diagram representing the control GSC can be seen in Fig. 5.

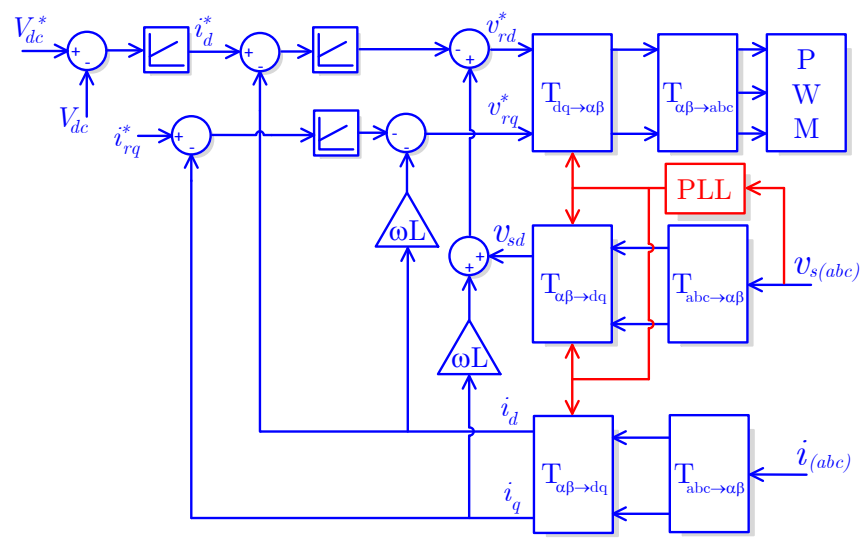

Fig. 5. GSC control [2].

The basic functions of the control shown in Fig. 5 is to keep constant the DC link voltage and to control reactive power in the GSC, by controlling the current and respectively. Fig. 6 shows the distribution of currents in the DC link of the back-to-back converter.

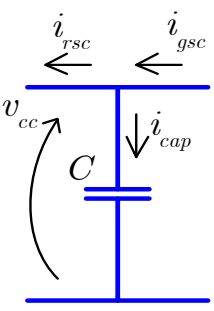

Fig. 6. DC link back-to-back converter.

This can be verified through the following expressions:

$$
\begin{gathered}
C \frac{d v_{c c}}{d t}=\frac{3 m_{1}}{4 \sqrt{2}} i_{d}-i_{r s c} \\
q_{r}=\frac{3}{2} v_{s d} i_{q}
\end{gathered}
$$

Where:

$C$ : capacitance of the DC link;

$i_{r s c}$ : Current in the DC link side of the rotor; $m_{1}$ : Modulation index of the GSC.

Analyzing equation (11) it is clear that by controlling the direct current component in GSC, it is possible regulate the voltage at DC link. Moreover, by controlling of component in quadrature of current in the GSC, it is possible to control reactive power in this converter. If it is necessary to operate with unity power factor is sufficient to adjust the reference current to zero $\left(\mathbf{i}_{\mathbf{q}}^{*}=\mathbf{0}\right)$ [3].

\section{STATCOM}

The first FACTS devices have appeared with the aim of compensate dynamically transmission lines and, thereby, increase system stability. Others FACTS devices can operate in voltage regulation at a given point of the power grid. In this class of devices its possible to find the STATCOM. In this topic, will be shown the structure of this device, as well as its control system.

\section{A. Structure of the STATCOM}

The schematic model of the STATCOM involved in its structure, a power inverter, a capacitor CC and a transformer coupling according to Fig. 7.

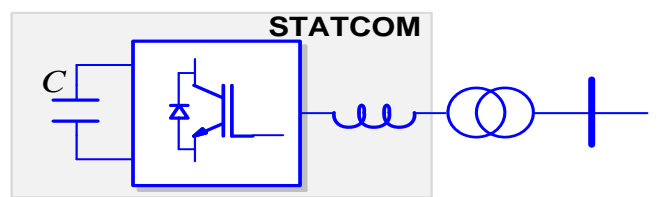

Fig. 7. Structure of the STATCOM.

The three-phase full-bridge inverter uses semiconductor switches like the GTO or IBGT, for switching and, through the energy stored in the capacitor $\mathrm{CC}$, is capable of generating a synchronous three-phase voltage on its output terminal [4]. Representative inverter topology is shown in Fig. 8. 


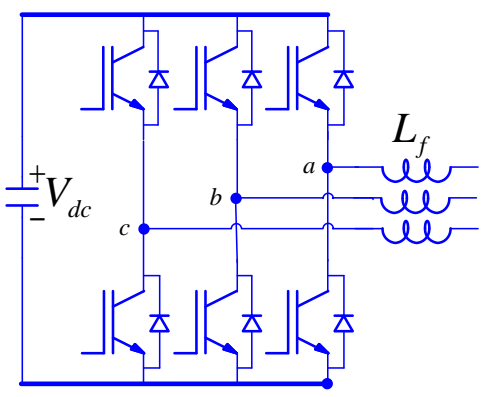

Fig. 8. Six-pulse inverter .

The STATCOM injects compensating current of variable magnitude at the PCC [6]. This is possible since the STATCOM can to work as a voltage source controlled by injecting reactive current in the system in a controlled manner.

One of the main benefits of STATCOM for a transmission line is the voltage regulation along the transmission line through reactive power compensation.

According to the literature [5], the compensation of reactive is used to regulate the voltage, both the mid-point (or intermediate) as the end of the line, preventing the instability of the voltage, as well as the dynamic control voltage in order to increase stability and improve the transient damping of power oscillations.

\section{B. System of STATCOM control}

In this paper, to control the STATCOM were used the concepts of the Theory of Instantaneous Active and Reactive Power, also known as pq Theory [7], besides the modulation hysteresis band [6].

Since the voltages and currents, in the more general case, can contain imbalances and harmonics, the real power and imaginary powers instantaneous will be formed by average components and oscillating, as shown in (13) and (14).

$$
\begin{aligned}
& p=\bar{p}+\tilde{p} \\
& q=\bar{q}+\tilde{q}
\end{aligned}
$$

Where the" $-"$ represents the power average value and the “ " represents the oscillating part. Several literatures such as [7] - [8], address pq Theory with more detail.

The block diagram of the control strategy shown in Fig. 9 has as variable output, the current of the converter injected into the electrical system in stationary coordinates $\alpha \beta$.

According to the control system shown reference signals of the real powers $(\overline{\mathrm{p}})$ and imaginary $(\overline{\mathrm{q}})$ are generated according to the conditions of compensation. These power references with the positive sequence voltage $\left(v_{\alpha \beta}^{+}\right)$ produce the reference compensation currents $\left(i_{\alpha \beta}^{*}\right)$. These currents are necessary to maintain the regulation of bus voltage $\mathrm{AC}$ or compensation from FP. The tension in the DC link is controlled by controlling the real power.

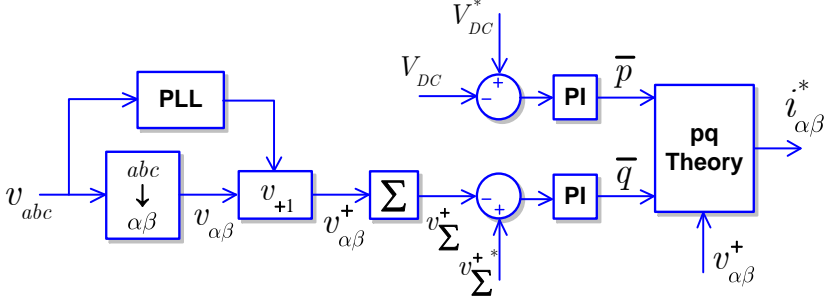

Fig. 9. Blocks diagram of the STATCOM.

Despite, in most cases, the grid voltage is composed, practically, by positive sequence component, may eventually, may contain undesirable components, such as negative sequence elements and harmonics, due presence of loads nonlinear on eletric system. Thus, the system must detect and set the positive sequence as reference.

The control of the FP when active, automatically disables the control voltage at the PCC. This happens because the control variable $(\bar{q})$ is the same in both modes.

To compensate for the power factor, it is necessary to calculate the reactive power of the load. One of the methods mentioned in [9] and [10] is called classic mode, which uses the equation for calculating the imaginary power, given by:

$$
q=v_{\beta} i_{\alpha_{\text {carga }}}-v_{\alpha} i_{\beta_{\text {carga }}}
$$

However, for obtaining the average value of the imaginary power $\bar{q}$, it is the use of a low-pass filter, as shown in Fig. 10.

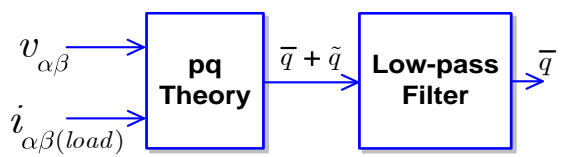

Fig. 10. Calculation of reactive power in load

The next session will discuss the results of simulations for a scenario that includes a wind turbine based on DFIG and static compensator STATCOM.

\section{Results of Simulations}

The computational tool used in this work was the PSCAD / EMTDC. Fig. 11 represents the model of the wind turbine developed in PSCAD, which consists of a wind turbine based on DFIG with rated power of 1.5 MW. The stator of the machine is directly connected to the common connection point (PCC), while the rotor is connected to the PCC through a converter AC-DC-AC, also known as back-to-back. Also connected to the PCC there are a nonlinear load and the device STATCOM.

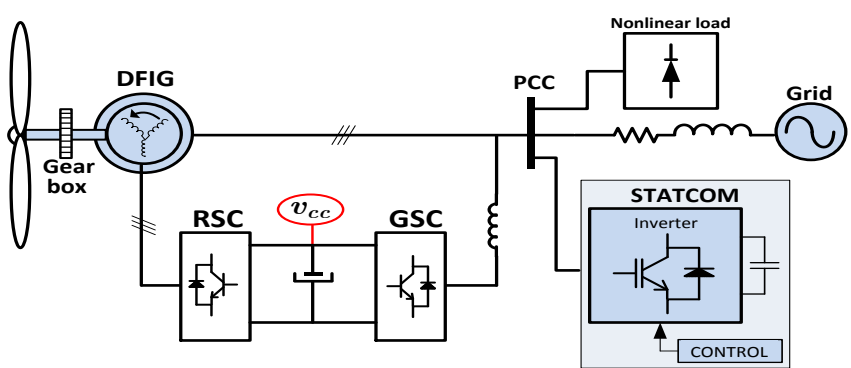

Fig. 11. Voltage at PCC with and without the STATCOM. 
The data of the simulated models are shown in Table I, II and III.

Table I. - DFIG Especifications

\begin{tabular}{|l|l|}
\hline DFIG parameters & Values \\
\hline \hline Rated Power & $1.5 \mathrm{MVA}$ \\
\hline Rated Voltage (L-L) & $690 \mathrm{~V}$ \\
\hline Rated Frequency & $60 \mathrm{~Hz}$ \\
\hline Stator Resistence & $0.0054[\mathrm{pu}]$ \\
\hline Wound rotor resistence & $0.00607[\mathrm{pu}]$ \\
\hline Stator leakage Inductance & $0.108[\mathrm{pu}]$ \\
\hline Wound rotor leakage Inductance & $0.110[\mathrm{pu}]$ \\
\hline Magnetizing inductance & $4.362[\mathrm{pu}]$ \\
\hline Moment of Inertia ( J=2H) & 0.5 \\
\hline Stator/Rotor Turns Ratio & 1 \\
\hline
\end{tabular}

Table II. - DC link an STATCOM Especifications

\begin{tabular}{l|l}
\hline DC Link parameters & Values \\
\hline \hline Capacitance & $1400 \mu \mathrm{F}$ \\
\hline Rated Voltage & $1200 \mathrm{~V}$ \\
\hline STATCOM parameters & Values \\
\hline \hline Rated Voltage & $690 \mathrm{~V}$ \\
\hline Rated Power & $1 \mathrm{MVA}$ \\
Capacitance & $1400 \mu \mathrm{F}$ \\
\hline
\end{tabular}

In order to characterize the simulated grid was calculated the ratio of Short Circuit $\rho_{\mathrm{cc}}$, as shown in Table III.

Table III. - Grid Especifications

\begin{tabular}{|l|l|}
\hline Grid parameters & Values \\
\hline \hline Resistence & $0.0250 \Omega$ \\
\hline Inductance & $0.00014 \mathrm{H}$ \\
\hline$\rho c c$ & 6 \\
\hline
\end{tabular}

According to [11] observed that the ratio of short-circuit system features a weak grid for $\rho_{\mathrm{cc}}<8$ and a strong grid for $\rho_{\mathrm{cc}}>20$. Therefore grid used here have weak feature.

The load RL connected to the PCC represents an active power of $358 \mathrm{~kW}$ and reactive power of $672 \mathrm{kvar}$. The voltage control in DC link through the GSC is also satisfied to $1.2 \mathrm{kV}$. The simulation results are summarized in the curves of active and reactive power of the stator machine, the CPC and the load connected to the system, beyond the different voltage and frequency at the PCC.

The Fig. 12 shows the behavior of the power flow of in the machine.

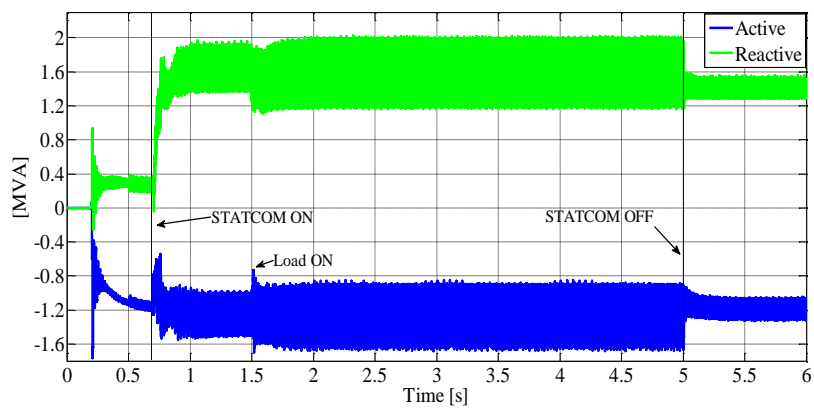

Fig. 12. Active and reactive powers in the machine.
Thus, it can be seen the active and reactive power control delivered by the DFIG stator through the RSC, keeping them in -1.2 MW and 1.5 Mvar, respectively.

Fig. 13 shows the behavior of voltage in the DC link of the back-to-back converter.

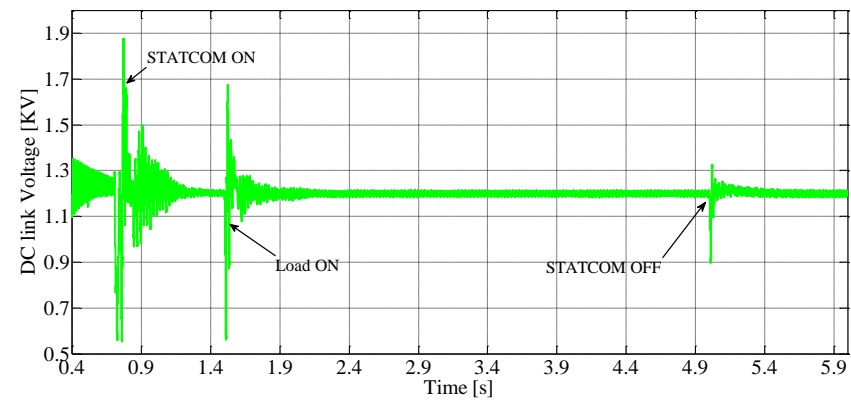

Fig. 13. DC link voltage.

You can see the control of the DC link voltage by controlling the GSC at $1.2 \mathrm{kV}$.

Was analyzed, from Fig. 14, the frequency behavior of the network, both with and without the STATCOM connected to the PCC.
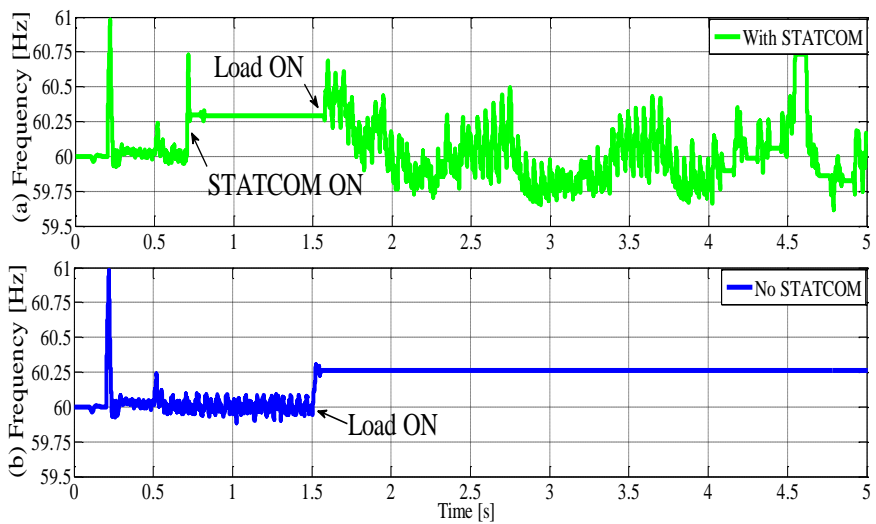

Fig. 14. Frequency at the PCC.

It can be seen that in (a), the mains frequency is maintained at appropriate levels, with little variation, even after the load connection at $\mathrm{t}=1.5 \mathrm{~s}$. Acceptable behavior occurs also in (b), where the frequency of the grid undergoes only a slight change when the load is connected to the system remaining constant throughout the remainder of the time.

The characteristic voltage curve on the bus that is connected to the load can be seen in Fig. 15.

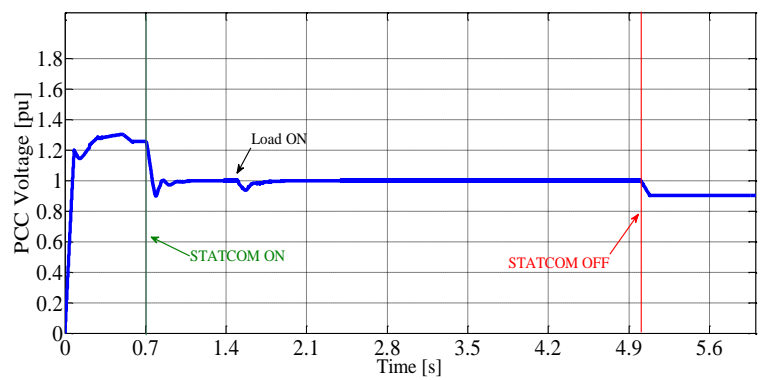

Fig. 15. PCC voltage. 
It is important to note that the voltage control is set at $1 \mathrm{pu}$ at the instant that the STATCOM is connected at the PCC. Even after connecting the load to keep the voltage controlled STATCOM at PCC. From $t=5 \mathrm{~s}$ there is no more voltage control, since the STATCOM is disconnected from the grid.

Fig. 16 shows the behavior of the STATCOM at system proposed in this paper, in which we compared the reactive power on PCC, on load and STATCOM.

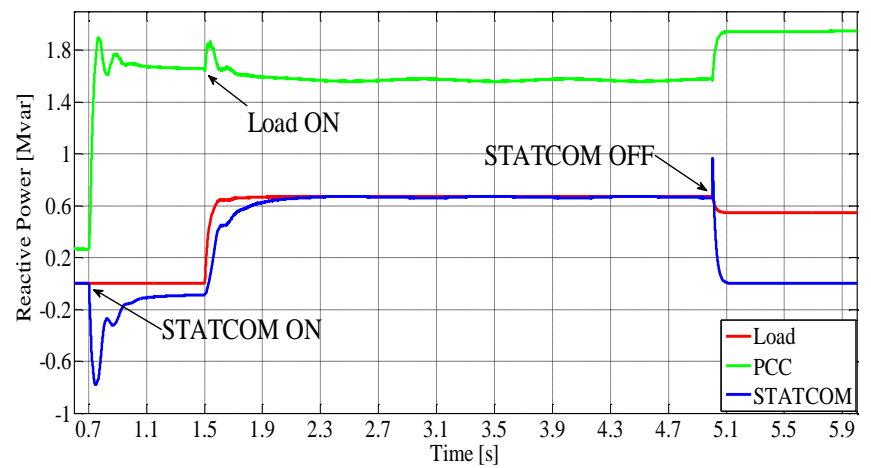

Fig. 16. Reactive Power Flow on PCC, on load and STATCOM.

From these results it can be seen that the DFIG can "see" the power required to maintain the voltage on PCC at $1 \mathrm{pu}$. From this figure, it is also possible to observe that the STATCOM "sees" the surplus reactive produced by the load, of the compensating efficiently.

The active power in the system is seen from Fig. 17.

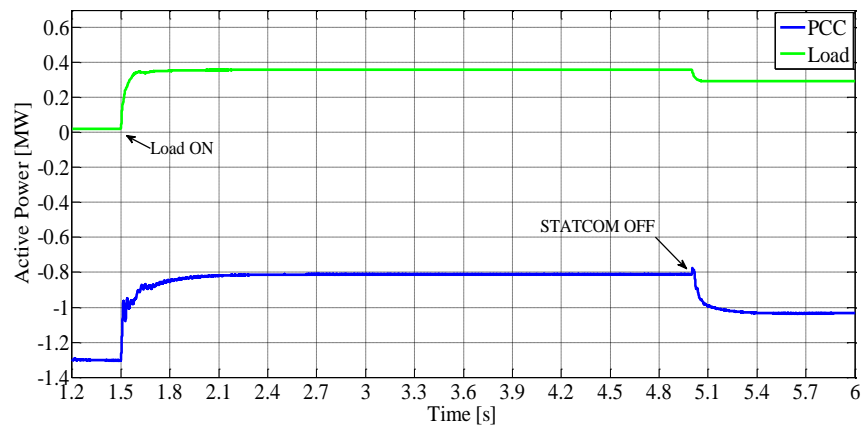

Fig. 17. Active power at PCC and load.

From the analysis of this figure, you can check the operation of the DFIG, injecting active power at the grid.

\section{Conclusion}

This paper presented the application of a STATCOM device with the DFIG, showing the advantages that this setting can bring to the system. According to the results presented showed that the basic requirements imposed by grid codes have been duly completed, which implies higher power quality and reliability of supply.

In case of contingencies, the turbine not only took on the role of keeping connected to the power grid, but also, the reactive power control, providing support voltage at the PCC. The STATCOM assumed its role in voltage controlling at the grid connection point.
The improvement in the quality of energy in the PCC was also verified by parameters such as rated voltage and frequency on the bus CA.

\section{Acknowledgement}

The authors would like to thank the Coordination of Superior Level Staff Improvement (CAPES) for the financial support for this research and the National Counsel of Technological and Scientific DevelopmentCNPq (486948/2012-9).

\section{References}

[1] S. Y. Liu, "Controle Direto de Potência em Gerador de Indução Duplamente Alimentado," dissertação mestrado, Dept. Eng. Elétrica, Univ. UFMG, Belo Horizonte, 2011.

[2] ANEEL. Agência Nacional de Energia Elétrica. Capacidade de Geração do Brasil. Brasília. Disponível em: <http://www.aneel.gov.br/aplicacoes/capacidadebrasil/capacidade brasil.cfm >. Access at: October, 06, 2013, 4:00 p.m.

[3] Lima, F.K.A. ; Luna, A. ; Rodriguez, P. ; Watanabe, E.H. ; Blaabjerg, F., "Rotor Voltage Dynamics in the Doubly Fed Induction Generator During Grid Faults" Power Electronics, IEEE Transactions on Volume: 25, Issue:1. 2010, pp: 118-130. Luna, A. ; Lima, F.K.A. ; Santos, D. ; Rodriguez, P. ; Watanabe, E.H. ; Arnaltes, S. , " Simplified Modeling of a DFIG for Transient Studies in Wind Power Applications" Industrial Electronics, IEEE Transactions on Volume: 58, Issue: 1. 2011, pp: 9-20.

[4] C. H. R. R. Santos, "Influência do STATCOM na estabilidade de Sistemas Elétricos de Potência," dissertação mestrado, Dept. Eng. Elétrica, UNIFEI, Itajubá, 2003.

[5] N. G. Hingorani, and L. Gyugyi, Understanding FACTS Concepts and Technology of Flexible AC Transmission Systems. Orlando: IEEE Press / Wiley-Interscience, 2000.

[6] N. Sumathy, and S. L. Prakash, "A STATCOM based control scheme for grid connected wind driven Induction Generator," Computing Communication \& Networking Technologies (ICCCNT)-Third International Conference, Coimbatore, India, IEEE, 2012.

[7] E. H. Watanabe and M. Aredes, "Teoria de Potência Ativa e Reativa Instantânea e Aplicações - Filtros Ativos e FACTS," Anais do XII Congresso Brasileiro de Automática-CBA Uberlândia, v. 1, p. 81-122, 1998.

[8] H. Akagi, E. H. Watanabe, and M. Aredes, Instantaneous Power Theory and Aplications to Power Conditioning. New Jersey: IEEE Press / Wiley-Interscience, 2007.

[9] A. J. Ortiz; M. Aredes; E. Bueno; P. Rodríguez, "Comparative study of the current and voltage controllers applied to the STATCOM", Indutrial Eletronics Society (IECON) - 33rd Annual Conference of the IEEE, Taipei, Taiwan, Nov. 5-7, 2012.

[10] A. J. Ortiz; M. Aredes; E. Bueno; P. Rodríguez; L. G. B. Rolim, "A New Current Control For The STATCOM Based On Secondary Order Generalized Integrators", IEEE, 2008.

[11] P. Jaim, Wind Energy Engineering, 1 ed.: McGraw-Hill Professional, 2010. 